\title{
A TECNOLOGIA OTIMIZANDO A COLETA E A DESTINAÇÃO CORRETA dOS RESÍDUOS SÓLIDOS: APLICATIVO ECOLETA
}

\author{
Jully Mariane Freire Xavier (IFRN) \\ jullymariane10@hotmail.com \\ Maria Beatriz de Oliveira Morais (IFRN) \\ mariabeatrizdeoliveiramorais@gmail.com \\ Maria Clara Rodrigues da Silva (IFRN) \\ maria-clara-2017@hotmail.com \\ Isllany Samara da Silva (IFRN) \\ isllanysamara27@hotmail.com
}

\section{Resumo:}

O presente artigo tem como objetivo desenvolver um sistema de recolhida de resíduos sólidos, trazendo como base a tecnologia e a Política Nacional de Resíduos Sólidos (PNRS). O trabalho justifica-se pela necessidade de melhorar a eficiência da coleta dos resíduos aplicando a logística com um método que foi estruturado em três etapas: I - Fundamentação teórica sobre o assunto abordado; II - Foi construída uma ideia que trouxesse benefícios e ao mesmo tempo uma solução, a partir da problemática desenvolvida; III - Descrição mais detalhada sobre o funcionamento do sistema e criação de ferramentas que fomentem as ações de conscientização, reutilização e inclusão. A etapa III foi subdividida em sete passos mais uma representação do software para que fosse plausível uma melhor planificação e aplicação do que foi estruturado. Os resultados apresentaram que a metodologia pode ser aplicada em qualquer cidade e, a mesma, é eficaz e inovadora para buscar conscientização da população com a separação e destinação correta dos resíduos sólidos.

(Palavras-Chaves: Resíduos Sólidos; Logística; PNRS; Tecnologia; Inovação.) 


\section{Introdução}

Mediante as grandes deficiências do Brasil nos sistemas de coleta e disposição final de resíduos sólidos, foi criada a Política Nacional de Resíduos sólidos (PNRS), Lei ${ }^{\circ}$ 12.305/10, que segundo o Ministério do Meio Ambiente, visa prevenir e reduzir a geração de resíduos, tendo como base a prática de hábitos de consumo sustentável e um conjunto de instrumentos para assegurar o aumento da reciclagem e da reutilização dos resíduos sólidos e a destinação ambientalmente correta dos rejeitos.

Ademais, o PNRS estabeleceu que todos os que participam do ciclo da vida de um produto, possuem responsabilidades em relação aos resíduos gerados por ele. A lei criou importantes metas para banir de vez os lixões e assim acabar com a poluição do solo por meio deles. Os catadores e catadoras de materiais recicláveis e reutilizáveis também foram introduzidos na lei, tendo participação tanto na coleta seletiva quanto na logística reversa.

O Brasil acabou não atingindo as expectativas, aumentando a produção de lixo, com baixo índice de reciclagem e ainda com a existência de lixões, que continuam contaminando o solo e as águas.

Diante disso, este trabalho tem como objetivo criar um sistema de coleta de resíduos sólidos eficaz, o qual os cidadãos poderão ver quando, onde e em qual horário a coleta irá passar. Nele encontraremos questões tratadas anteriormente, como a conscientização, reutilização e a inclusão. Trazendo como base a tecnologia que está ao alcance de quase todos os cidadãos nos dias atuais e o Plano Nacional de Resíduos Sólidos.

Os resíduos sólidos, sem a devida condução e tratamento podem causar inúmeros prejuízos à sociedade e ao meio ambiente. Entre eles, estão as doenças através das substâncias contidas nesses resíduos, poluição do ar, da água e do solo, degradação ambiental e vários outros. Este sistema irá trazer benefícios tanto para o meio ambiente, que é o principal prejudicado com toda a poluição causada pela gestão inadequada dos resíduos sólidos, quanto para os cidadãos e empresas que dependem de algum desses resíduos como matéria prima.

\section{Referencial Teórico}

O referencial teórico do presente trabalho foi estruturado em três tópicos, sendo eles: Política Nacional de Resíduos Sólidos, Logística Reversa e Economia Circular.

\subsection{Política Nacional de Resíduos Sólidos (PNRS)}


A Política Nacional de Resíduos Sólidos, Lei n 12.305/2010, integra a Política Nacional do Meio Ambiente, Lei ${ }^{\circ}$ 6.938/1981. Conforme o Ministério do Meio Ambiente, a PNRS contém instrumentos importantes para que o país enfrente os principais problemas ambientais, sociais e econômicos devido o manejo inadequado dos resíduos sólidos.

A prática do consumo sustentável e o aumento da reciclagem e da reutilização dos resíduos e a destinação ambientalmente adequada contribui a prevê a prevenção e a redução na geração dos resíduos

Na visão de Gouveia (2012), os resíduos sólidos, quando não gerenciados corretamente, podem ter impactos no ar, liberando partículas e outros poluentes atmosféricos. Uma das formas que os resíduos sólidos geram impactos no ar é por meio da decomposição anaeróbica da sua componente orgânica que produz GEE (gás de efeito estufa) e especialmente o metano ( $\mathrm{CH} 4)$, considerado um dos principais responsáveis do aquecimento global.

A PNRS se torna inovadora pela inclusão dos catadores e catadoras de materiais recicláveis e reutilizáveis e a logística reversa na coleta seletiva.

A lei contribuiu significativamente para as discussões sobre a Logística Reversa de produtos já consumidos. "Sem dúvida a PNRS foi um acelerador de preocupações e discussões empresariais na área de pós-consumo" (Leite, 2010).

\subsection{Logística Reversa}

Também conhecida como logística inversa, logística reversa é a área da logística com foco no retorno de materiais já utilizados para o processo produtivo, visando o reaproveitamento ou descarte apropriado de materiais e a preservação ambiental. Quando uma empresa de logística consegue empregar um processo de logística reversa de maneira ainda lucrativa, ela está alcançando a sustentabilidade econômica e ambiental do seu negócio.

Chaves e Alcântara (2010, p. 2) definem que a logística reversa diz respeito ao fluxo de produtos ou embalagens que voltam à empresa por algum motivo como devoluções de clientes, retorno de embalagens, retorno de produtos para atender à legislação, defeito, falta de atendimento às expectativas, erro de pedidos, excesso de estoque, danificação ou contaminação do produto e produtos fora de linha (Surplus), dentre outros.

Segundo a PNRS, artigo 3, parágrafo 12, da Lei 12.305, de 2 de agosto de 2010: a logística reversa consiste em um instrumento de desenvolvimento econômico e social caracterizado 
por um conjunto de ações, procedimentos e meios destinados a viabilizar a coleta e a restituição dos resíduos sólidos ao setor empresarial, para reaproveitamento, em seu ciclo ou em outros ciclos produtivos, ou outra destinação final ambientalmente adequada.

De acordo com Leite (2009), a Logística Reversa tem sido citada com frequência e de forma crescente em livros modernos e Logísticos Empresarial, em artigos internacionais e nacionais, demonstrando sua aplicabilidade e interesse em diversos setores empresariais apresentando novas oportunidades de negócio no Supply Chain Reverso, criado por esta nova área da Logística Empresarial. No Brasil, mais recentemente, seu interesse empresarial tem sido demonstrado por inúmeras palestras, seminários e consultas que temos realizado em associações, empresas e universidades e o interesse acadêmico pela sua inclusão como disciplina curricular em cursos de especialização em Logística Empresarial.

A logística reversa traz melhorias para a empresa, aumentando o nível de qualidade, reduzindo os custos de produção, é um diferencial para as empresas, se tornando uma vantagem competitiva, além de cumprir a lei, já que a logística reversa está prevista na PNRS.

\subsection{Economia Circular}

Segundo a Fundação Ellen MacArthur (EMF, 2012), trata-se de um modelo de economia industrial intencionalmente "restaurador", projetado para recuperar de forma circular o produto de suas atividades.

Uma alternativa atraente que busca redefinir a noção de crescimento, com foco em benefícios para toda a sociedade. Isto envolve dissociar a atividade econômica do consumo de recursos finitos, e eliminar resíduos do sistema por princípio.

De acordo com Stahel (2016), a economia circular se destaca através da transformação de bens que estão no final de sua vida útil em recursos para outros processos, fechando ciclos em ecossistemas industriais e minimizando resíduos, sendo então capaz de mudar a lógica econômica, pois substitui a produção por suficiência: reutilizar o que for possível, reciclar o que não pode ser reutilizado, reparar o que está danificado e remanufaturar o que não pode ser reparado.

Apoiada por uma transição para fontes de energia renovável, o modelo circular constrói capital econômico, natural e social. Ele se baseia em três princípios:

- Eliminar resíduos e poluição por princípio; 
- Manter produtos e materiais em ciclo de uso;

- Regenerar sistemas naturais.

De acordo com a revista Start\&Go (2018, pág. 03)

\begin{abstract}
A Economia Circular ultrapassa o âmbito e foco estrito das ações de gestão de resíduos e de reciclagem, visando uma ação mais ampla, desde o redesenho de processos, produtos e novos modelos de negócio até a otimização da utilização de recursos ("circulando" o mais eficientemente possível produtos, componentes e materiais nos ciclos técnicos e/ou biológicos). Visa assim o desenvolvimento de novos produtos e serviços economicamente viáveis e ecologicamente eficientes, radicados em ciclos idealmente perpétuos de reconversão a montantes e a jusante.
\end{abstract}

Ciclos técnicos e biológicos:

O modelo da economia circular faz uma distinção entre ciclos técnicos e biológicos.

O consumo se dá apenas nos ciclos biológicos, onde alimentos e outros materiais de base biológica (como algodão e madeira) são projetados para retornar ao sistema através de processos como compostagem e digestão anaeróbica. Esses ciclos regeneraram os sistemas vivos, tais como o solo, que por sua vez proporcionam recursos renováveis para a economia.

Ciclos técnicos recuperam e restauram produtos, componentes e materiais através de estratégias como reuso, reparo, remanufatura ou (em última instância) reciclagem.

A economia circular visa acabar com o conceito de lixo, de uma forma que cada material é aproveitado em fluxos periódicos, o que possibilita sua trajetória de produto em produto. A economia circular vem sendo adotada por vários setores da sociedade, oferecendo um novo modelo de pensamento com a capacidade de iluminar o desafio de transformação dos modelos atuais de desenvolvimento industrial e econômico.

\title{
3. Metodologia
}

Este trabalho consiste na elaboração de um software, o Ecoleta, tendo como objetivo a melhora de forma eficaz da gestão de resíduos sólidos em meios urbanos. A base deste trabalho foi através de amplas pesquisas bibliográficas e obras científicas que apresentam conceitos e estudos sobre o tema. 
Diante disso, o trabalho se dividiu em três etapas: I - foi desenvolvida a fundamentação teórica sobre o assunto abordado; II - foi construída uma ideia que trouxesse benefícios e ao mesmo tempo uma solução, a partir da problemática desenvolvida anteriormente; III foi feita a descrição mais detalhada sobre o funcionamento do sistema e criação de ferramentas que fomentem as ações de conscientização, reutilização e inclusão.

A fim de melhor descrever o funcionamento do sistema e as ferramentas que nele se encontrarão, foi desenvolvido um passo a passo, onde a partir dele o software poderá ser bem visualizado:

- Passo 1: Os caminhões de lixo existentes nas cidades serão readaptados para possuir subdivisões de modo que as matérias orgânicas fiquem separadas dos plásticos, que fiquem separados dos metais e assim sucessivamente. Essa separação deverá ser facilitada pela população, onde cada cidadão terá o dever de separar os resíduos em sua residência.

- Passo 2: Os caminhões falados anteriormente também deverão possuir rastreadores, que mostrará onde e em que horário os mesmos deverão passar em um determinado lugar, assim a população usuária do aplicativo poderá se programar para colocar seus resíduos para fora de casa.

- Passo 3: Utilização de ferramentas para a conscientização da população sobre a importância de uma gestão de resíduos sólidos eficaz, serão elas: Ecological Footprint (Pegada Ecológica), calendário com datas e horários de ações, onde a prefeitura em parceria com algum órgão ou grupo poderá notificar para falar sobre o assunto, um segundo calendário com as datas marcadas que o determinado cidadão contribuiu com a coleta, além de notificações diversas sobre a coleta.

- Passo 4: Os catadores vão ser empregados nos caminhões de coleta, auxiliando nas atividades, já as cooperativas vão servir como ponto de apoio para os materiais coletados.

- Passo 5: Ao abrir o aplicativo o usuário deverá se cadastrar com seu CPF e criar uma senha para poder acessar a ferramenta e as atividades do aplicativo. A partir desse cadastro o sistema e a prefeitura terão o controle da coleta e da contribuição de cada cidadão. 
- Passo 6: As empresas que tiverem algum resíduo sólido como sendo matéria prima de seus produtos finais, poderão entrar em contato com a prefeitura ou com a secretaria de meio ambiente para comprar os mesmos e assim ajudar na ação de reutilização.

- Passo 7: E por fim, o cidadão que contribuir com a coleta, separando os resíduos do modo adequado irá receber um desconto na taxa de lixo do IPTU, referente a sua contribuição.

\subsection{Software Ecoleta:}

Figura 1 - Guia Inicial

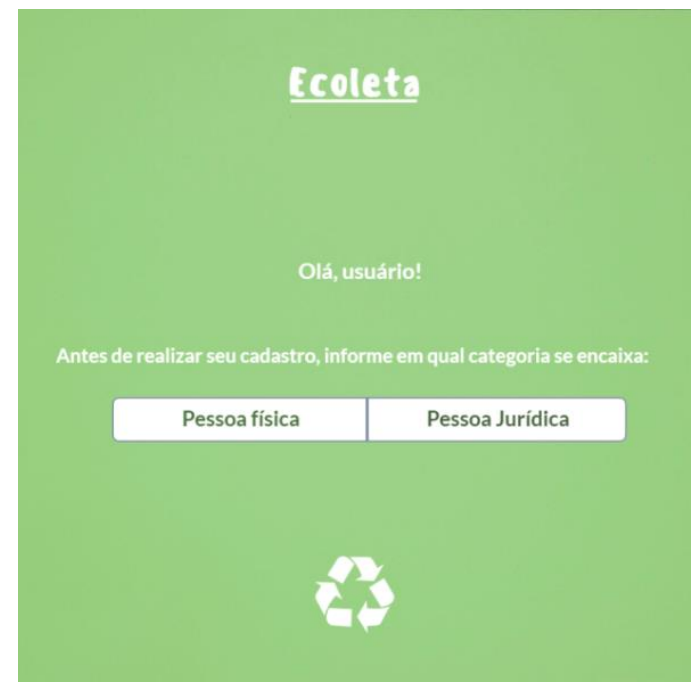

Fonte: Autores (2020)

Figura 2 - Guia de Cadastro

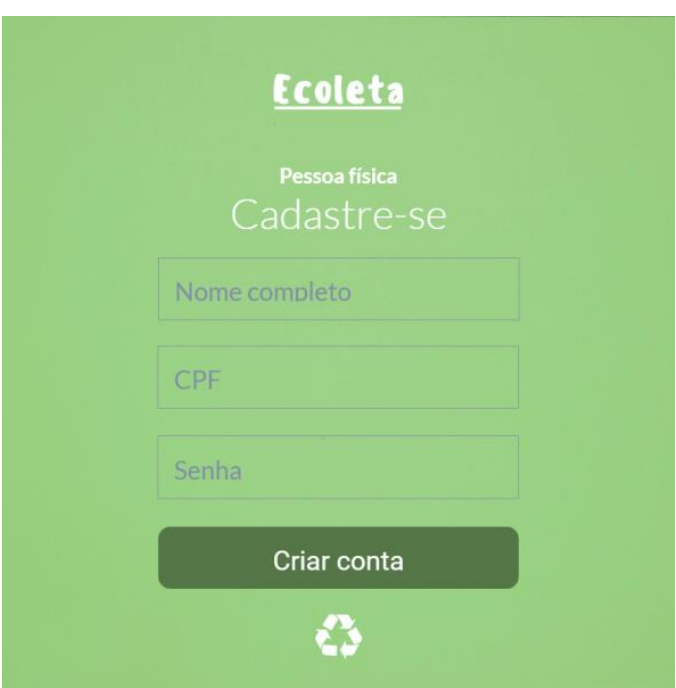

Fonte: Autores (2020) 
Figura 3 - Guia de Perfil

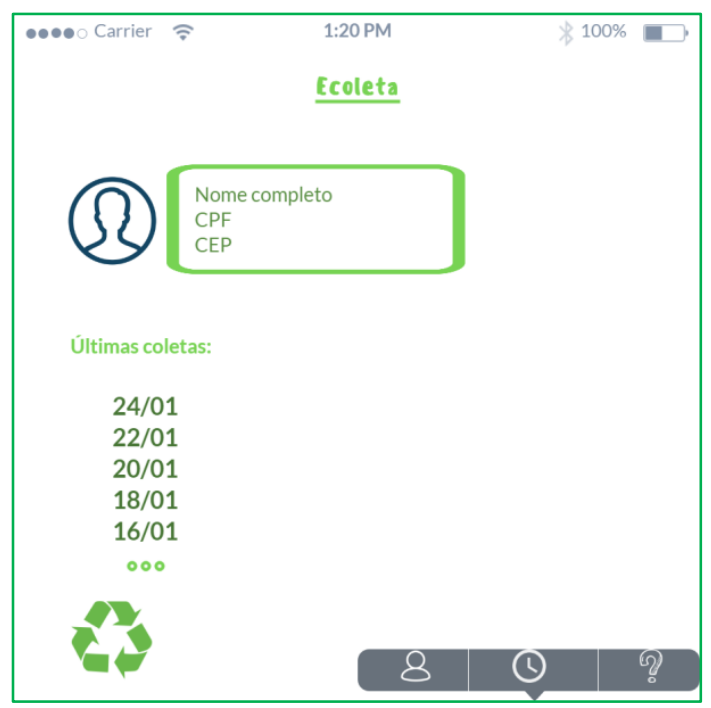

Fonte: Autores (2020)

\section{Resultados}

A partir do uso do software apresentado, será possível enxergar resultados significativos tanto para o meio ambiente, quanto para os seres humanos.

Com o rastreamento dos caminhões de lixo, os cidadãos poderão se programar para colocar seus resíduos para fora de casa, de acordo com a disponibilidade das datas e horários exatos, além de poder acompanhar o trajeto desses caminhões em tempo real, conforme mostra a Figura 4. Evitando-se, a partir disso, que esse lixo produzido fique durante horas ou dias, exposto nas ruas, correndo o risco de ser violado, podendo provocar a obstrução de córregos, pontes e bueiros pelo acúmulo de lixo, que são levados pela água das chuvas. 
Figura 4 - Guia de Rastreamento

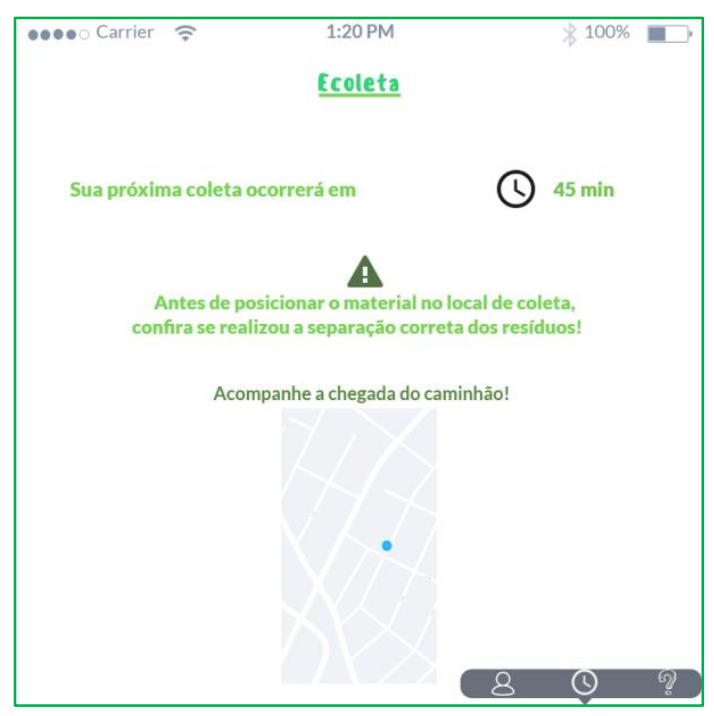

Fonte: Autores (2020)

Essa obstrução acarreta enchentes que além de provocar muitas perdas materiais, é um grande causador de doenças como a leptospirose, além de outros vetores causadores de doenças, como baratas, moscas, ratos, escorpiões e mosquitos. Diante disso, o Ecoleta poderá contribuir com a redução de doenças e transtornos à sociedade.

Mais um resultado que poderá ser obtido pelo uso do Ecoleta, é o trabalho de conscientização e educação ambiental com os usuários, conforme retratado na Figura 5, pois nem todos estão cientes sobre a importância do controle de resíduos sólidos pela população, já que o descarte deles é algo dinâmico e constante.

Figura 5 - Guia de Conscientização

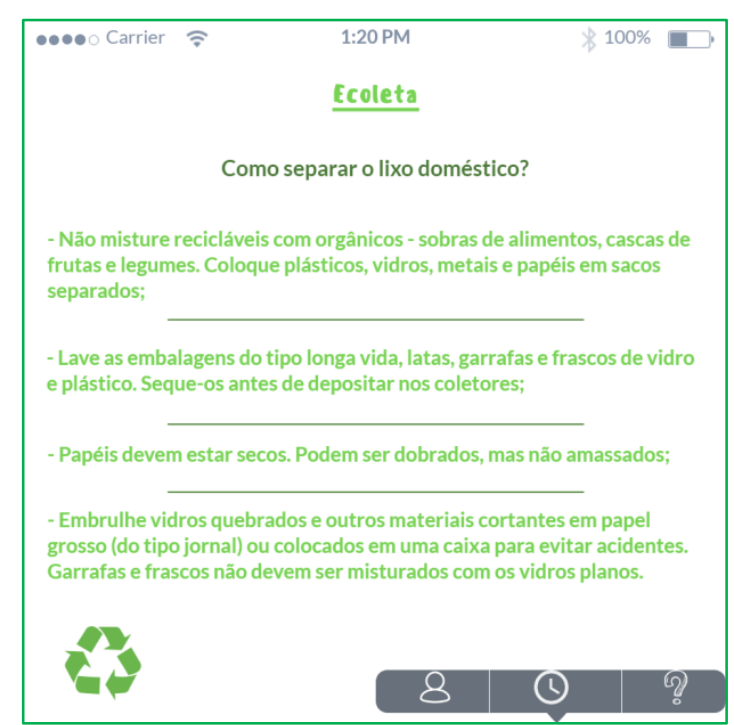


O aplicativo dispõe de ferramentas para trabalhar a conscientização e práticas relacionadas à gestão dos resíduos sólidos, como o Ecological Footprint (também conhecido como pegada ecológica). Essa ferramenta propõe aos usuários medir a quantidade de recursos naturais renováveis necessários à manutenção do seu estilo de vida, com isso será possível que os usuários comecem a rever os seus hábitos. Além do Ecological Footprint, também estarão disponíveis calendários no aplicativo, cujo primeiro mostrará datas e horários em que a prefeitura irá fazer ações para a melhoria do meio ambiente e para a conscientização da população de acordo com os fatos mostrados pela prefeitura. O segundo calendário terá como objetivo mostrar todos os dias que o usuário contribuiu para a coleta, e o mesmo receberá notificações com o intuito de lembrar horários e quão perto o caminhão está da sua residência, entre outras. $\mathrm{O}$ uso dessas ferramentas tornará a utilização dos $3 R^{\prime} s$ uma prática do dia a dia de cada pessoa

Outro resultado que será obtido, é a melhoria do trabalho e, consequentemente, a inclusão dos catadores de materiais reutilizáveis e recicláveis, que é um dos instrumentos do PNRS, tanto na logística reversa como na coleta exclusiva; cuja maioria se encontra trabalhando em situações precárias, de forma autônoma e dispersa nas ruas e em lixões, como também em grupos, por meio de organizações produtivas em cooperativas e associações. Muitos deles acabam tendo contato direto com os resíduos, causando doenças já que pouquíssimos catadores usam materiais de proteção. Visando a melhoria de vida dessas pessoas, o presente aplicativo considera os catadores como empregados nos caminhões, assim poderão ter emprego mais humano e com todos os seus direitos. Já as cooperativas servirão como ponto de apoio para os materiais coletados, assim os materiais recicláveis não se misturaram com os rejeitos.

Outro benefício proposto pelo Ecoleta é a redução da taxa de lixo do Imposto Predial e Territorial Urbano (IPTU). Os usuários, ao cadastrarem-se no aplicativo, informam o Cadastro de Pessoa Física (CPF) ou o Cadastro Nacional da Pessoa Jurídica (CNPJ), como exposto na Figura 1, e a ferramenta de controle de coletas é responsável por distinguir as pessoas que terão direito ao desconto no pagamento da taxa de lixo do IPTU.

Determinadas empresas utilizam resíduos sólidos como principal matéria-prima dos seus produtos e, outra vantagem deste método é o fato das pessoas jurídicas poderem contactar 
com a prefeitura ou com a secretaria de meio ambiente para comprar os materiais e, assim, ajudar no processo de reutilização.

\section{Conclusão}

Dado o exposto, o intuito deste trabalho foi desenvolver um método eficaz e inovador de coleta de resíduos sólidos de uma cidade metropolitana, aliando logística à tecnologia, por meio de um software. Tendo em vista que a separação, coleta e destinação correta dos resíduos têm importante relevância para a sociedade e a natureza, é imprescindível uma atenção especial à problemática já apresentada.

Neste sentido, a aplicação de uma estratégia progressista de coleta se apresenta como necessária. $\mathrm{O}$ aplicativo Ecoleta traz uma esperança de conscientização municipal, podendo até mesmo ser estadual.

Os resultados apresentados autenticaram a eficácia do mecanismo proposto neste trabalho, destacando-se a importância do PNRS, com o objetivo de se obter melhorias na sociedade com pequenos atos que, quando somados, tornam-se gigantes e fazem uma enorme diferença no Planeta Terra.

Desta forma, é lícito assegurar que o método sugerido mostra-se conveniente, podendo ser empregado nas prefeituras, tendo em vista a dificuldade de gerenciamento dos resíduos sólidos, cujo propósito, a partir da coleta, é de reduzi-los ou, até mesmo, aboli-los. 


\section{Referências:}

ALMEIDA, Ana Victoria da Costa. Revalorização do caroço de açaí em uma beneficiadora de polpas do município de Ananindeua/PA: proposta de estruturação de um canal reverso orientado pela PNRS e logística reversa. GEPROS. Gest. Prod. Oper. Sist., Bauru, São Paulo - SP (Brasil), 2017.

Blog da Saúde. Lixo mal descartado pode causar acidentes e doenças. 2017. Disponível em: <http://www.blog.saude.gov.br/index.php/53136-lixo-mal-descartado-pode-causar-acidentes-e-doencas >. Acesso em: 12 de Dezembro de 2019.

BRASIL. Lei n ${ }^{\circ} 12.305$ de 02 de Agosto de 2010; Institui a Política Nacional de Resíduos Sólidos. Disponível em: <https://www.mma.gov.br/cidades-sustentaveis/residuos-solidos/politica-nacional-de-residuos-solidos.html> Acesso em: 29 de Novembro de 2019.

BRASIL. Logística Reversa. Ministério do Meio Ambiente. Disponível em: <https://www.mma.gov.br/cidadessustentaveis/residuos-perigosos/logistica-reversa.html>. Acesso em: 12 de Dezembro de 2019.

DE ARAAÚJO, Thaís Duek; DE QUEIROZ, Adriane Angélica Farias Santos Lopes. ECONOMIA CIRCULAR: BREVE PANORAMA DA PRODUÇÃO CIENTÍFICA ENTRE 2007 E 2017. (ENGEMA). São Paulo, 2017.

ECONOMIA Circular. Ellen Macarthur Foundation, $2017 . \quad$ Disponível em: <https://www.ellenmacarthurfoundation.org/pt/economia-circular-1/conceito>. Acesso em: 10 de Dezembro de 2019.

ECONOMIA Circular. $\quad$ Start\&Go, $2018 . \quad$ Disponível em: <https://www.startandgo.pt/m/pt/article?id=1277\&name=ECONOMIA-CIRCULAR-O-QUE-E $>$. Acesso em: 10 de Dezembro de 2019.

GOUVEIA, Nelson. Resíduos sólidos urbanos: impactos socioambientais e perspectiva de manejo sustentável com inclusão social. Revista SciELO. São Paulo, 2012.

GUARNIERI, Patricia. Logística Reversa no Brasil: Avanços e Perspectiva - Entrevista com o professor Paulo Roberto Leite. Revista em Gestão, Inovação e Sustentabilidade - Brasília, V 2, n. 1, p. 267 - 270, jun 2016.

JUCÁ, José Fernando Thoomé. Disposição Final dos Resíduos Sólidos Urbanos no Brasil. Congresso Brasileiro de Geotecnia Ambiental. Porto Alegre (RS), 2014.

LEITE, Paulo Roberto. Logística Reversa - Nova Área da Logística Empresarial. Revista Tecnologística, Edit Pulicare, São Paulo, 2002.

MAIELLO, Antonella; BRITTO, Ana Lucia Nogueira de Paiva; VALLE, Tatiana Freitas. Implementação da Política Nacional de Resíduos Sólidos. Revista Adm. Públicavol.52, no. 1, Rio de Janeiro, 2018.

RIBEIRO, Flavio de Miranda; KRUGIANSKAS, Isak. (ENGEMA) Encontro Internacional sobre Gestão Empresarial e Meio Ambiente. São Paulo - SP, 2014.

SANTOS, Jadir P. dos Santos; SALUM, Alfredo Oscar; JOINHAS, Luzia Aparecida; DA SILVA, Robson de Oliveira. Uma Abordagem Teórico-conceitual da Logística Reversa, através da Cooperativa de Catadores de Resíduos na Zona Leste de São Paulo. Gestão e Tecnologia para a Competitividade. São Paulo, 2013. VIANA, João José. Administração de materiais: um enfoque prático. São Paulo: Atlas 2010. 